\title{
Effect of the Aggressive Environment on the Damage of a Glass Polyester Composite Developed by Hand Layup Process
}

\author{
Nabila Belloul, ${ }^{1}$ Hassiba Hamadache, ${ }^{1}$ Ali Ahmed Benyahia, ${ }^{2}$ and Aîcha Serier ${ }^{1}$ \\ ${ }^{1}$ Laboratory of Coating, Materials and Environment (LRME), University M'Hamed Bougara of Boumerdes, 35000 Boumerdes, Algeria \\ ${ }^{2}$ Advanced Mechanic Laboratory (LMA), University of Sciences and Technology Houari Boumediene (USTHB), \\ 16024 Bab Ezzouar, Algeria
}

Correspondence should be addressed to Nabila Belloul; nbelloul@gmail.com

Received 12 February 2015; Revised 23 March 2015; Accepted 24 March 2015

Academic Editor: Belal F. Yousif

Copyright (C) 2015 Nabila Belloul et al. This is an open access article distributed under the Creative Commons Attribution License, which permits unrestricted use, distribution, and reproduction in any medium, provided the original work is properly cited.

\begin{abstract}
This work treats the behavior of a glass fibre/unsaturated polyester (UP) composite with structural defects subjected to the attack of two corrosive solutions: $\mathrm{H}_{2} \mathrm{SO}_{4}$ and $\mathrm{NaOH}$. The gravimetric analysis, the uptake mass of the resin, and the interfaces in the composite are established according to the proportion of the matrix/composite. The obtained results showed that, in the acidic solution, the glass fibre and the fibre/matrix interface absorption share is more significant than the alkaline solution. While the Fourier transform infrared analysis (FT-IR) of the UP resin revealed the presence of chemical degradation phenomenon (hydrolysis), the fibre corrosion was characterized by the atomic absorption analysis (AAS). The fibres/matrix interfaces degradation was confirmed by microscopic observations (SEM). The diffusion kinetics of the both acid and alkaline solutions and chemical and mechanical degradation are affected by the presence of the pores in elaborated material.
\end{abstract}

\section{Introduction}

The elaboration of glass fiber/polyester composite materials by the hand layup process is one of the methods that is used currently in different manufactories as fishing boats, automobile and tanks for chemical products. It is a simple and inexpensive process: glass or other reinforcing mat or woven fabric or roving is positioned manually in the mold, and resin is poured, brushed, or sprayed over and into the glass plies. However, since entrapped air is removed manually with rollers, the formation of pores or vacuums is inevitable.

According to Jeong [1], a value threshold of $1 \%$ of porosity is tolerated. Although, the composites elaborated by the hand layup process do not satisfy this criterion, they largely satisfy user requirements. Moreover, if these materials have been widely characterized for a passive environment, it is not the same for an aggressive one.

The studies carried out on the degradation of polymeric materials containing UP resin in acidic and alkaline solutions show that the absorption mechanism is governed by a hydrolytic degradation phenomenon. Gu et al. [2] report that the attack of polyesters by the hydroxide ions is localized on the surface. This localization is related to the low polarity of the polyesters that limits the diffusion of these ionic species to the heart of polymer. This is why the hydrolysis intensifies on the surface, and there is the formation of shorter and soluble polymeric chains in the alkaline solution. According to Poulard [3], the average molecular mass of the polyester chains in the heart of material almost does not vary with the exposure duration. Knowing that, in the composites case, the reinforcement plays the stabilizing role, the hydrolytic attack is activated mechanically by the load presence under the differential expansion effect between the various material phases that create strong internal stresses in the fibre/matrix interface [4]. Gu et al. [2] report that, according to the absorption of the liquid, the fibre surface is presented a chemical degradation which is related to ion exchanges process or leaching process. It is about the extraction of alkaline ions in surface $(\mathrm{Na}, \mathrm{Al}, \mathrm{B}, \mathrm{Ca}, \ldots$, etc.) and their replacements by protons. From the mechanical behavior, it was established in experiments that the physicochemical variations relating to the liquids diffusion in the composite did not, automatically, generate losses of mechanical properties in the material [5]. 
It should be noted that the literature has not been interested in hand layup process, although it is widely used. Therefore, we focus on behavior of glass/UP used in fishing boats subject to spills of acid solution $\left(\mathrm{H}_{2} \mathrm{SO}_{4}\right)$ and alkaline one $(\mathrm{NaOH})$.

\section{Materials}

The materials of this study are UP resins and composites glass/UP. The resin used is an unsaturated polyester (POLYLITE 442-100) supplied by REICHHOLD based on orthophthalic acid. As for the gelcoat, it is EUROGEL GCP, an isophthalic polyester resin charged in white pigments. The composite is prepared by hand layup process and staking sequence is selected [mat 300/mat 450/2[mat 600]/woven 500/mat 300] (reduced sequence of one used in naval construction). The average thickness of the composite plates is about $4.89 \pm 0.36 \mathrm{~mm}$ with $35.65 \mathrm{wt} \%$ glass fibres reinforcement. The average porosity is of $2.3 \%$ with diameters varying mainly between $1 \mu \mathrm{m}$ and $200 \mu \mathrm{m}$ (determined by optical microscopy).

In all cases the materials (resins and composites) were manufactured at laboratory temperature $\left(20 \pm 2^{\circ} \mathrm{C}\right)$ with $2 \%$ of methyl ethyl ketone peroxide solution (PMEC 50) and $1 \%$ of cobalt octoate as accelerator, as recommended by the suppliers. It was then postcured using a cycle of $24 \mathrm{~h}$ at room temperature then $16 \mathrm{~h}$ at $40^{\circ} \mathrm{C}$. This cure cycle was chosen as it was shown to correspond to a cure state similar to that obtained on industrial components [6].

The resin specimens are prepared by casting in aluminum molds, the composite specimens are cut from the plate described above, and some resin films samples are elaborated by casting then compression between two glass plates. The form of these used different specimens depend to the test types to realize.

The resin, composites, and films specimens are immersed separately in $\mathrm{H}_{2} \mathrm{SO}_{4}$ solution with concentration of $28 \%$ and in $\mathrm{NaOH}$ solution with concentration of $3 \mathrm{~mol} / \mathrm{L}$, at room temperature during 1200 and 120 hours, respectively.

\section{Techniques}

A comparison between the results obtained for the immersed and nonimmersed samples is carried by some techniques.

The absorption of acidic and alkaline solutions was followed by gravimetry. The resin specimens $(15 \times 15 \times$ $\left.2 \mathrm{~mm}^{3}\right)$ and the composites specimens $(15 \times 15 \times 4.89 \pm$ $0.36 \mathrm{~mm}^{3}$ ) were, first, marked, weighted, and then immersed in different solutions at room temperature. Specimens were periodically withdrawn from the solutions and weighed with a $0.1 \mathrm{mg}$ precision balance. The solution uptakes (Mt (\%)) during the immersion are calculated as follows:

$$
M(\%)=\frac{m(t)-m(0)}{m(0)} * 100,
$$

where $m(0)$ and $m(t)$ are the weight uptakes at time $=0$ and time $=t$, respectively.
An analysis by infrared spectroscopy was carried out on polyester films immersed in $\mathrm{H}_{2} \mathrm{SO}_{4}$ and $\mathrm{NaOH}$ at 1200 hours and 120 hours, respectively. This analysis was performed with SHIMADZU 8400 instrument with a resolution of $8 \mathrm{~cm}^{-1}$ in absorbance at room temperature.

The atomic absorption spectroscopy tests (Solaar Thermo Elemental machine) were carried out on the acidic and alkaline solutions having contained the resin and composite materials during 120 and 1200 hours, respectively. As for the $\mathrm{X}$-ray fluorescence analysis (Philips Magic X machine), it is carried out on a nonimmersed UP resin samples. That makes it possible to check if the mineral elements present in the solutions come from the resin or the composite.

The analysis of the microstructure of our material and the possible effects of chemical degradation on the fibre/matrix interface is carried out using electronic scan microscopy (Quanta 600 instrument) to 15 and $20 \mathrm{Kv}$.

To characterize the effects of the acidic and alkaline solutions on the mechanical behavior, tensile (ISO 527) and three-point bending test (NF T51-001) were carried out on a series of five samples. The tests were performed on Zwick/Roell Z050 machine at controlled displacement with a speed of $2 \mathrm{~mm} / \mathrm{min}$ at room temperature. The dimensions of the various samples are presented in Figure 1.

\section{Results and Discussion}

It is noted that, by simple visual observations, only the samples immersed in $\mathrm{NaOH}$ have a change of color: the gelcoat became russet-red, whereas the remainder of the material translucent initially became white opaque.

4.1. Weight Change. The results of the gravimetry test for the resins and composites samples immersed in $\mathrm{H}_{2} \mathrm{SO}_{4}$ and $\mathrm{NaOH}$ are illustrated in Figures 2(a) and 2(b).

These results show a weight saving for the samples immersed in sulphuric acid (Figure 2(a)). The acidic diffusion in the resin is pseudo fickian. It is characterized, first, by a quasi-linear phase up to 21 days of immersion followed by a weight uptake deceleration and this is without saturation. The same way is registered for the composite, but with weight uptake acceleration as from 30 days. These recorded kinetics of diffusion are traditional for this type of material. They are similar to those observed by several authors in other mediums $[4,6,7]$.

According to Perrot [6], the weight uptake of the UP resins is due to the reaction of the water of the solution according to a hydrolysis phenomenon:

$$
\mathrm{RCOOR}^{\prime}+\mathrm{H}_{2} \mathrm{O} \longrightarrow \mathrm{RCOOH}+\mathrm{R}^{\prime} \mathrm{OH}
$$

According to Lebel [8], the UP resin degradation by hydrolysis produces an acidic solution that increases the material hydrophilie. On the other hand, Kumar et al. [4] reported that the high concentration of the sulphuric acid and its cumbersome nature prevent the diffusion of water in material. Thus, we can say that the recorded curves translate the existence of the two phenomena: hydrophilie and blocking of absorption at the same time. 


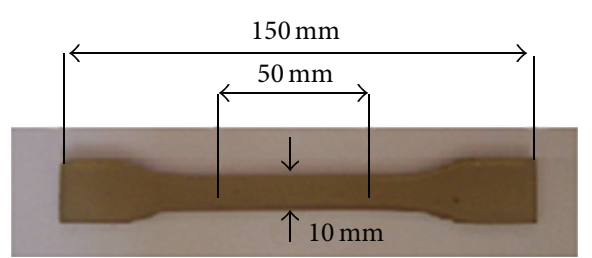

(a)

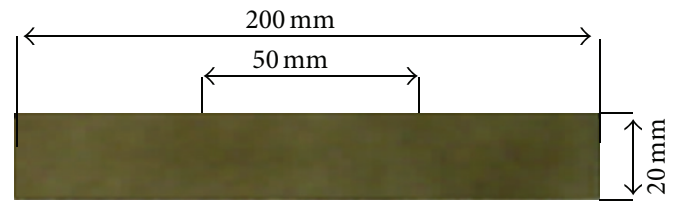

(c)

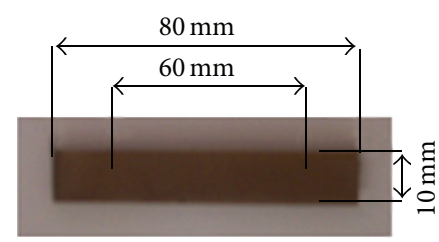

(b)

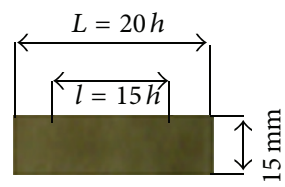

(d)

FIGURE 1: Specimen dimensions for tensile tests and bending tests, respectively: resin (a) $h=3 \mathrm{~mm}$ and (b) $h=4 \mathrm{~mm}$ and composite (c) and (d) $h=4.89 \pm 0.36 \mathrm{~mm}$.

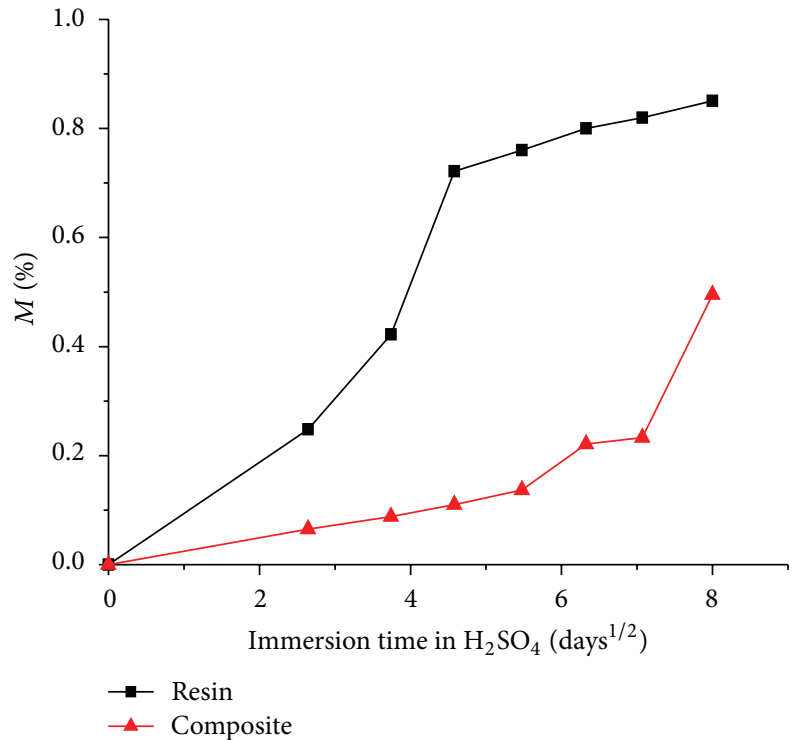

(a)

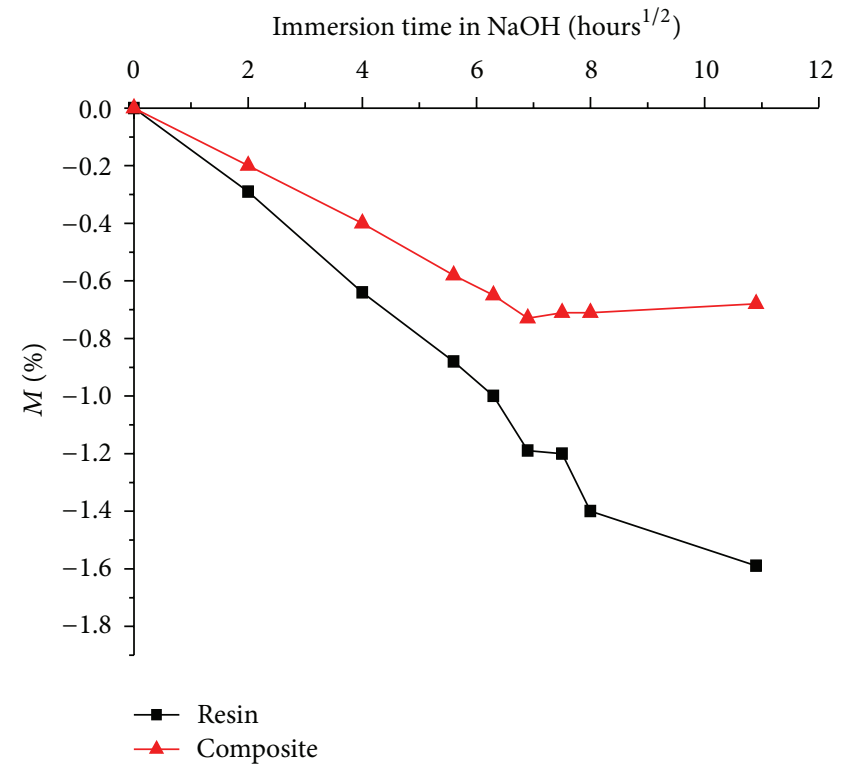

(b)

FIgURE 2: Kinetics diffusion in the resin and the composite in immersion in $\mathrm{H}_{2} \mathrm{SO}_{4}$ (a) and $\mathrm{NaOH}$ (b).

As for the composite, the hydrolysis will generate cracks and cavities and will thus cause the diffusion of the acid towards the fibre/matrix interface responsible for the corrosion phenomenon of glass fibres following the $\mathrm{HSO}^{4-}$ or $\mathrm{SO}_{4}{ }^{2-}$ ions reaction with the alkaline component of the latter (metal ions). That explains the acceleration of the weight uptake phenomenon in the case of the composite at the end of immersion.

In the same way for the $\mathrm{NaOH}$ solution, the diagrams of this Figure 2(b) show a mass loss as well for the resin for the composite. The mass loss evolution appears quasi linear except for the composite where a pseudosaturation stage is recorded as from 64 hours of immersion.

The mass loss corresponds mainly to cuts of chains after hydrolysis of the ester groupings of the resin catalyzed by
$\mathrm{OH}^{-}$ion of the medium. It also corresponds to the fragments dissociation having low molecular weights, in addition to the mass loss of glass fibres under the alkaline solution effect [2]. As for the pseudosaturation stage, it would represent a carbonation occurring on the surface of the composite (formation of a white powder on the material surface) and prevents partially any exchange with environment.

The variation of these results between the resin and the composite is due to the presence of fibres, the fibre/matrix interfaces, the structural defects, and porosity. The effect of these various parameters on the kinetics of diffusion is illustrated in Figure 3.

The weight uptake calculation of the resin in the composite and the interfaces was done according to Gellert and Turley [9] and Perrot [6] works. The mass uptake of the resin 


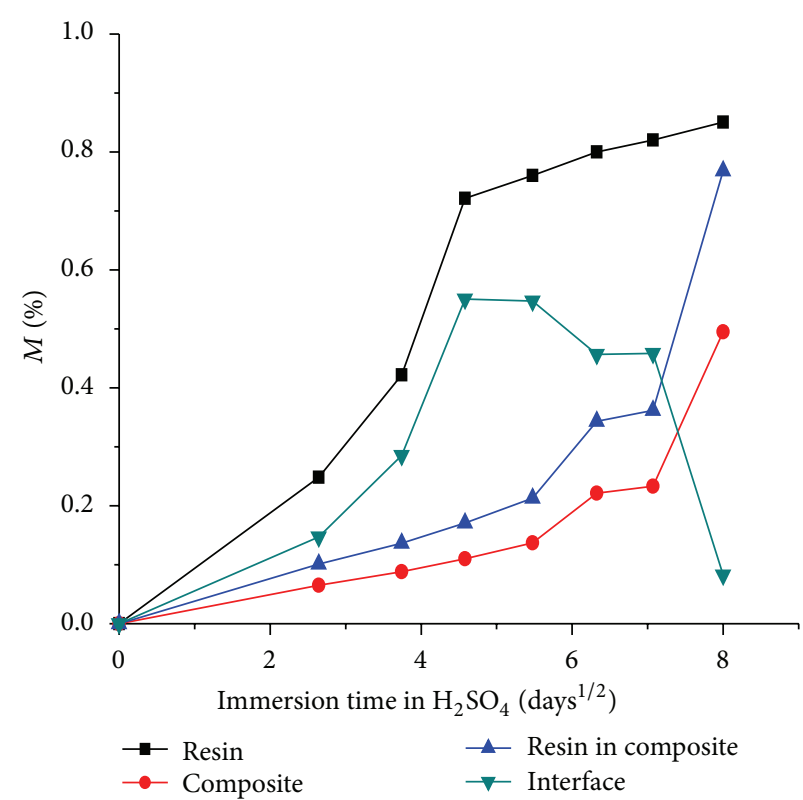

(a)

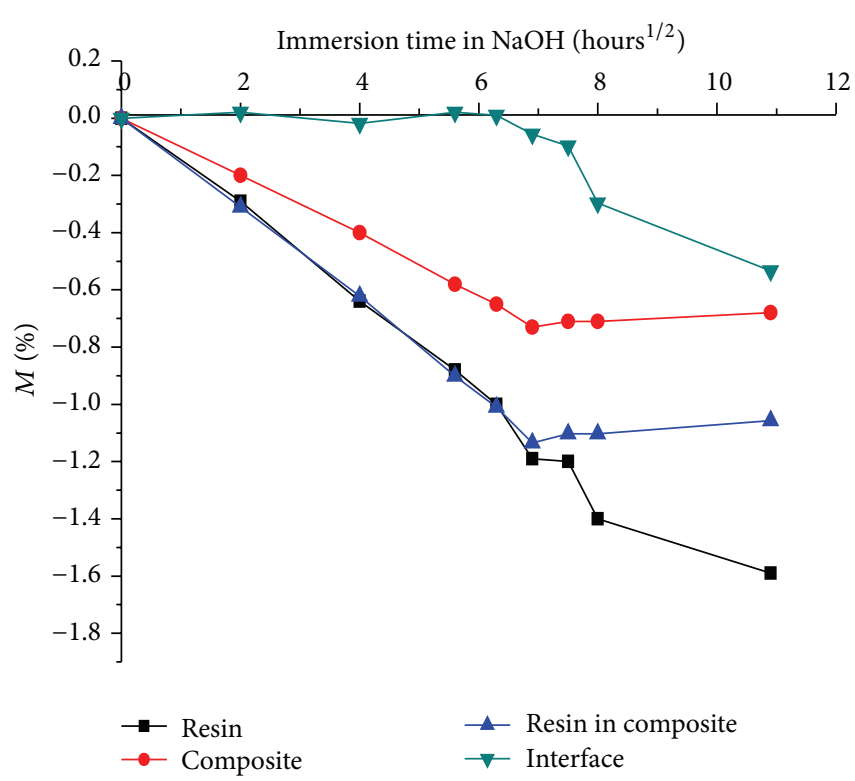

(b)

FIGURE 3: Weight uptake of the resin alone, the composite, the resin in the composite, and the interface (a) in $\mathrm{H}_{2} \mathrm{SO}_{4}$ and (b) in $\mathrm{NaOH}_{\text {. }}$

in the composite is standardized according to the proportion of the matrix in composite; it is given by the relationship between the mass uptake of the composite and the rate of the matrix mass. As for the mass uptake allotted to the interfaces, it is estimated by withdrawing the mass uptake of the resin in the composite of the mass uptake of the resin alone.

These results show that the decrease of the resin hydrophilie is due to the presence of the reinforcement. For the first days of immersion, in the case of the acid, both the resin and the fibres/matrix interfaces show an absorption that evolves in a progressive way. That means that during the first days of immersion, the two hydrolyses phenomena and aggression of the interface occur simultaneously. With time, the damage of the fibres/matrix interface increases the contact surface of the resin with the acid, which increases the absorption rate; it strips, also, the fibres that start to corrode in their turn. On the other hand, for the $\mathrm{NaOH}$, the alkali hydrolysis phenomenon is prevalent up to 40 hours of immersion. Beyond this duration, it is the beginning of the attack of the interface.

4.2. Fourier Transform Infrared Spectroscopy (FT-IR). The results obtained are represented by the superposed absorption spectra (Figures $4(\mathrm{a})$ and $4(\mathrm{~b})$ ) recorded before and at the end of the immersion, respectively. The interpretation of the results is made on the basis of comparison between the spectra obtained in addition to the results of latter study $[2,10]$.

The infrared spectra obtained for the UP film before immersion (Figures 4(a) and 4(b)) represent the vibration bands characteristic of the various groupings constituting the UP resin of general formula (see Scheme 1).

Table 1 summarizes these principal bands.
TABLE 1: Attributions of the principal characteristic bands.

\begin{tabular}{|c|c|c|}
\hline $\begin{array}{l}\text { Wavenumbers } \\
\left(\mathrm{cm}^{-1}\right)\end{array}$ & $\begin{array}{c}\text { Peak } \\
\text { number }\end{array}$ & Vibration mode \\
\hline $3527-3449$ & 1 & $\begin{array}{l}v(\mathrm{O}-\mathrm{H}) \text { hydroxyls of the } \\
\text { alcohol functions }\end{array}$ \\
\hline 3089 & 2 & $v(\mathrm{C}-\mathrm{H})$ aromatics \\
\hline 2989 & 3 & $\begin{array}{l}v(\mathrm{O}-\mathrm{H}) \text { hydroxyls of the } \\
\text { acid functions }\end{array}$ \\
\hline 1731 & 4 & $v(\mathrm{C}=\mathrm{O})$ ester \\
\hline $1273-1071$ & 5 & $v(\mathrm{C}-\mathrm{O}-\mathrm{C})$ ether \\
\hline $1638-1452$ & - & $\begin{array}{l}\delta(-\mathrm{CH}),-\mathrm{CH}_{2} \text { et }-\mathrm{CH}_{3} \\
\text { aromatic cycle }\end{array}$ \\
\hline 989 & 6 & $\mathrm{C}=\mathrm{C}$ polyester \\
\hline 904 & 7 & $\mathrm{C}=\mathrm{C}$ styrene \\
\hline
\end{tabular}

The spectra of the resins immersed in the two mediums confirm well the presence of the hydrolysis phenomena already revealed by the tests of kinetics diffusion (Figure 2).

The intensity of the $\mathrm{O}-\mathrm{H}$ vibrations band characteristic of the alcohol function $\left(3500 \mathrm{~cm}^{-1}\right)$ and that of the $\mathrm{O}-\mathrm{H}$ vibrations band characteristic of the acid function $\left(2982 \mathrm{~cm}^{-1}\right)$ increases for the two mediums of immersion. On the other hand, the intensity of the bands characteristic of the $\mathrm{C}-\mathrm{O}-$ $\mathrm{C}$ connections of the ester group $\left(1250 \mathrm{~cm}^{-1}\right)$ decreases. This reduction is due, in the case of the $\mathrm{NaOH}$, to the cut of the $\mathrm{C}-\mathrm{O}-\mathrm{C}$ connections to form a carboxylic salt and an alcohol according to

$$
\mathrm{RC}-\mathrm{O}-\mathrm{CR}^{\prime}+\mathrm{NaOH} \longrightarrow \mathrm{RC}-\mathrm{O}-\mathrm{Na}+\mathrm{R}^{\prime} \mathrm{OH}
$$

The reduction in the bands characteristic of the $\mathrm{C}-\mathrm{O}-\mathrm{C}$ of ester group in $\mathrm{H}_{2} \mathrm{SO}_{4}$ is less intense than in $\mathrm{NaOH}$; it is due 


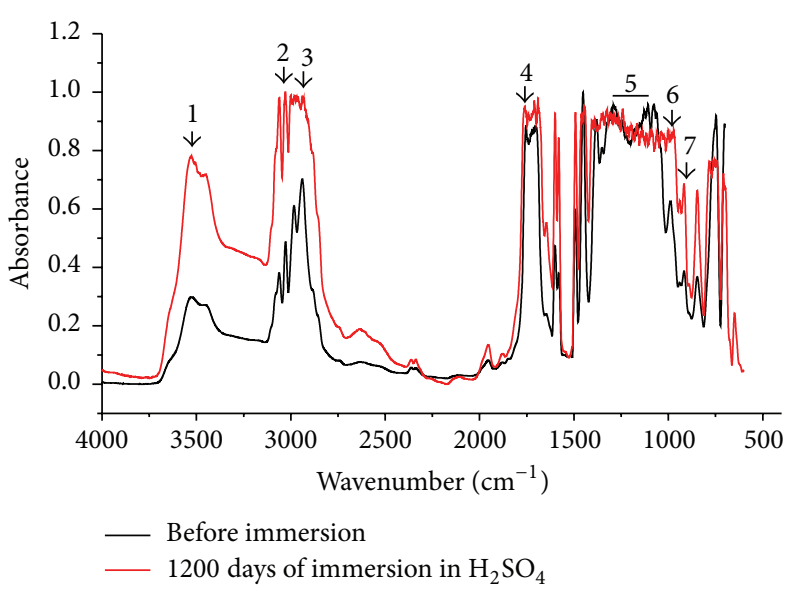

(a)

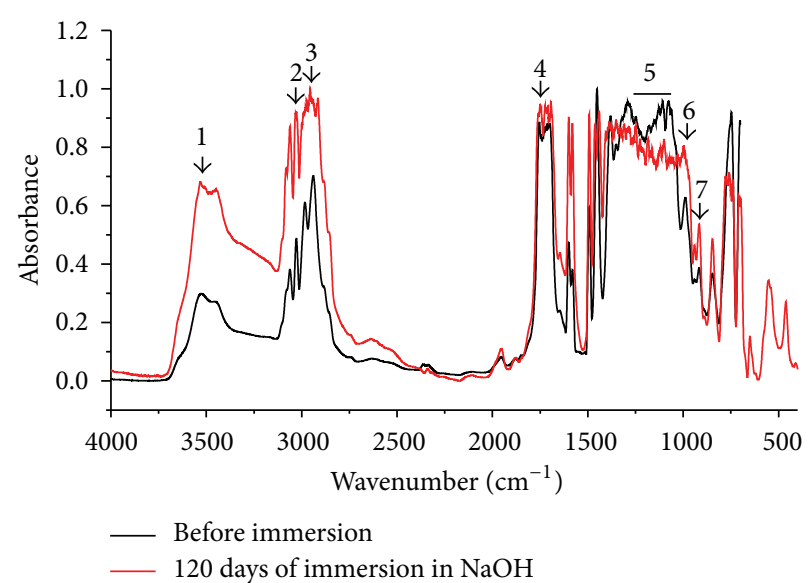

(b)

FIGURE 4: Infrared spectra of the polyester films degraded under (a) $\mathrm{H}_{2} \mathrm{SO}_{4}$ and (b) $\mathrm{NaOH}$.

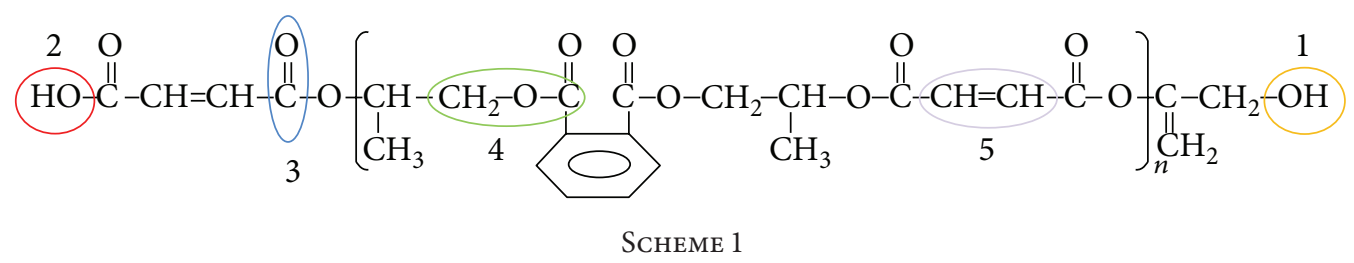

to the reaction of this connection with the water of the acid solution.

According to these results obtained, we can deduce that the alkaline attack occurs on the level of the connections macromolecular chains (scission of chains), which agrees well with the results reported by $\mathrm{Gu}$ et al. [2]. On the other hand, the acid attack also leads to the scission of chains but moreover with the formation of new final groupings $\mathrm{OH}$ and $\mathrm{COOH}$ with intensities stronger than in the case of the $\mathrm{NaOH}$.

As for the presence of the peaks characteristic of the styrene (S) and polyester (UP) vinyl groups $\left(904 \mathrm{~cm}^{-1}\right.$ and $989 \mathrm{~cm}^{-1}$, resp.), it means that the conversion rate into styrene and polyester is not total even after postcuring (incomplete crosslinking). This incomplete crosslinking increases the solubility of material in the acids and the bases and reduces its resistance. This results in the increase in the intensity of the peaks characteristic of the styrene and polyester vinyl group of immersed material. Figures 4(a) and 4(b) show, also, that the hydrolysis of film immersed in $\mathrm{NaOH}$ appears faster than that in $\mathrm{H}_{2} \mathrm{SO}_{4}$. In fact, at 120 hours of immersion in $\mathrm{NaOH}$, there are practically the same rates of hydrolysis as at 1200 hours in the sulphuric acid. The speed of hydrolysis in the alkaline medium is due to the formation of the carboxylate anion (equation (3)) which makes this medium more aggressive [11].

4.3. Atomic Absorption Spectrometry (AAS) and X-Ray Fluorescence. The analysis by $\mathrm{X}$-ray fluorescence, of the resin before immersion, showed the presence of traces of aluminum $(\mathrm{Al})$, sodium $(\mathrm{Na})$, calcium $(\mathrm{Ca})$, and magnesium
$(\mathrm{Mg})$ used in the additives composition of the resin. As for the results of the analysis by atomic absorption, they are presented in Table 2.

These results show the presence of the $\mathrm{Mg}, \mathrm{Ca}$, and $\mathrm{Al}$ elements in the acid and alkaline solutions having contained the resin during 1200 hours and 120 hours, respectively. These elements initially present in the resin migrate towards the various solutions according to the concentration gradient and/or by scrubbing by $\mathrm{H}_{2} \mathrm{SO}_{4}$ and $\mathrm{NaOH}$. The presence of cobalt (Co) in the alkaline solution, present initially in the resin like accelerator in the form of big molecules of cobalt octoate, reveals well the aggressiveness of this solution and its higher capacity of dissociation than that of the acid.

These results show, also, that the minerals rates in the solutions having contained the composite are more significant than those detected in the solutions having contained the resin. That translated the attack of glass fibres by these solutions. They show, also, which of the corrosion of glass fibres is more significant in the acid medium than in the alkaline one. It is a process of ions exchange or about a leaching process [2].

4.4. Observation by Scan Electron Microscopy (SEM) of Composite Material. For the best identification of the damage phenomena that could generate degradation in the right of the composites interfaces, some observations by electronic microscope (SEM) were realized. These observations were carried out on nonimmersed composites then on those immersed during 21 and 50 days in $\mathrm{H}_{2} \mathrm{SO}_{4}$ and during 40 and 120 hours in $\mathrm{NaOH}$. The images observed are illustrated by Figures 5, 6, and 7. 
TABLE 2: Contents of the metal elements in the acid and alkaline solutions.

\begin{tabular}{|c|c|c|c|c|}
\hline \multirow{2}{*}{ Solutions } & \multicolumn{4}{|c|}{ Elements (mg/L) } \\
\hline & Co & $\mathrm{Mg}$ & $\mathrm{Ca}$ & $\mathrm{Al}$ \\
\hline $\mathrm{H}_{2} \mathrm{SO}_{4}$ after 1200 hours (cont. resin) & 0,0000 & 0,1426 & 1,8542 & 0,9620 \\
\hline $\mathrm{H}_{2} \mathrm{SO}_{4}$ after 1200 hours (cont. composite) & 0,0000 & 8,5755 & 50,2541 & 36,4050 \\
\hline $\mathrm{NaOH}$ after 120 hours (cont. resin) & 0,0446 & 0,3600 & 1,2419 & 0,9620 \\
\hline $\mathrm{NaOH}$ after 120 hours (cont. composite) & 0,5633 & 0,4624 & 6,8449 & 8,5569 \\
\hline
\end{tabular}

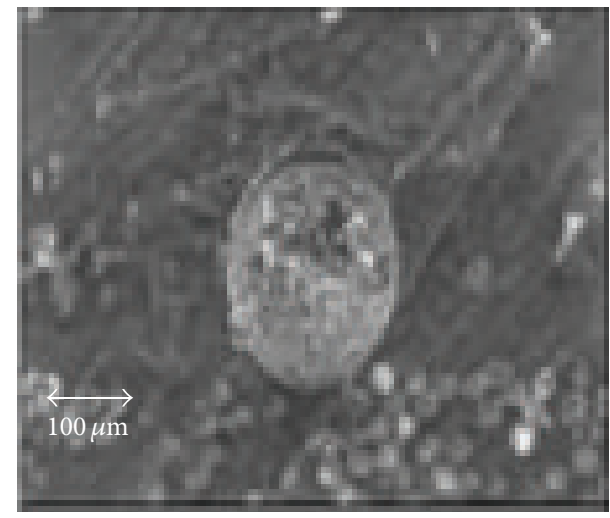

(a)

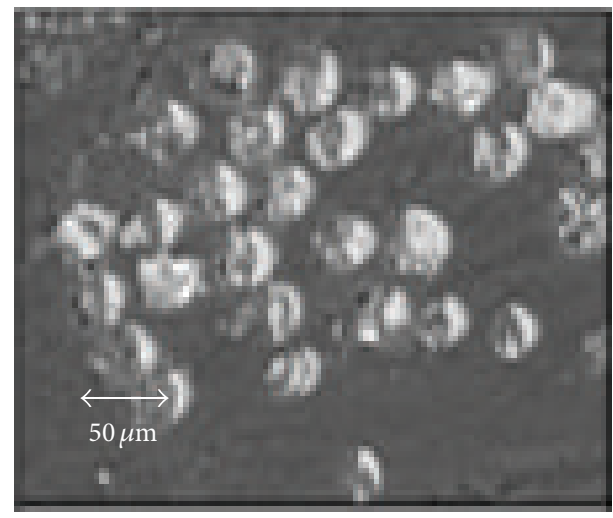

(b)

FIGURE 5: Observations with the SEM of composite material before immersion.

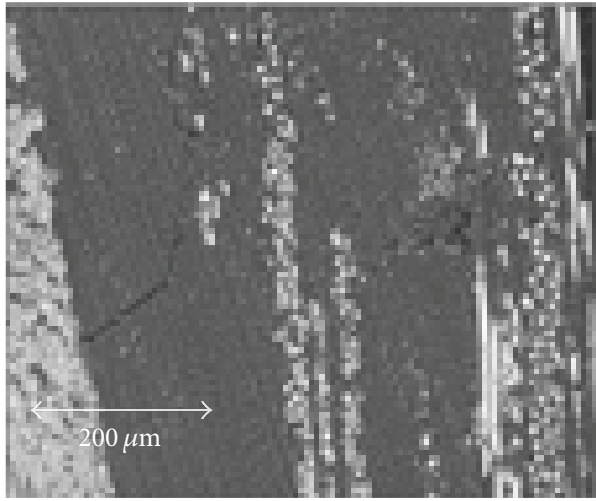

(a)

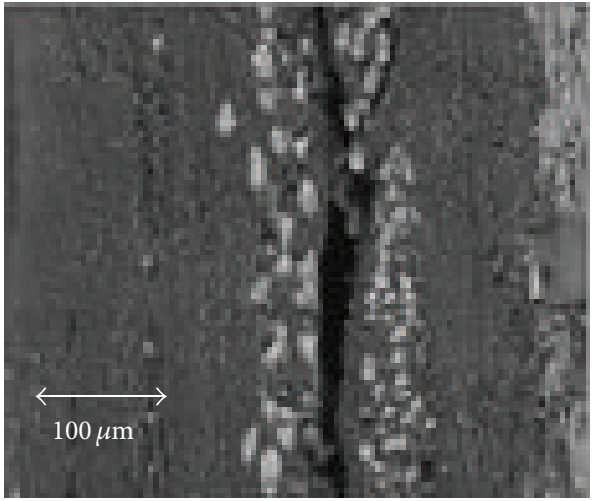

(b)

FIGURE 6: Observations with the SEM of composite material immersed in the sulphuric acid (a) after 21 days and (b) after 50 days.

For the nonimmersed composite, Figures 5(a) and 5(b) show the presence of pores of rather significant size going up to $200 \mu \mathrm{m}$. These pores can be easily occupied by the various solutions. As result, the contact surface with the resin is increased to affect the material degradation.

These images show that, after 21 days of immersion in the sulphuric acid, the resin in the composite has a cracking (Figure 6(a)) which can facilitate the diffusion of the acid and reach the fibre/matrix interfaces. Indeed, Figure 6(b) shows that after 50 days of immersion, degradation reaches well the interfaces.

These images show, also, that after 40 hours of immersion in $\mathrm{NaOH}$ (Figure 7(a)), the degradation of the interfaces starts to settle and becomes very clear after 5 days of immersion (Figure 7(b)). This last figure shows a macrocrack with washing away of fibres. These various reports show the aggressiveness of the two solutions $\left(\mathrm{H}_{2} \mathrm{SO}_{4}\right.$ and $\left.\mathrm{NaOH}\right)$ on the composite through the degradation of the fibre/matrix interface.

\subsection{Mechanical Tests}

4.5.1. Tensile Tests. Behaviors in traction of the resin and the composite immersed in the sulphuric acid $\left(\mathrm{H}_{2} \mathrm{SO}_{4}\right)$ and the sodium hydroxide $(\mathrm{NaOH})$ for various times of immersion are represented by Figures 8 and 9 .

The stress-strain curves of the resin immersed in $\mathrm{H}_{2} \mathrm{SO}_{4}$ and $\mathrm{NaOH}$ (Figure 8) have the same evolution and translate 


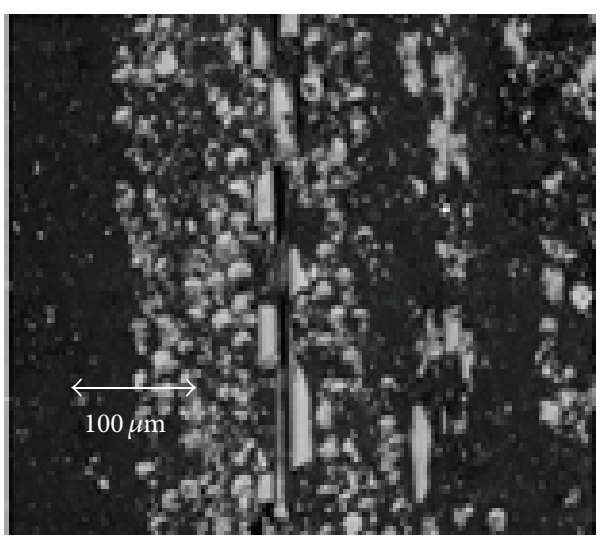

(a)

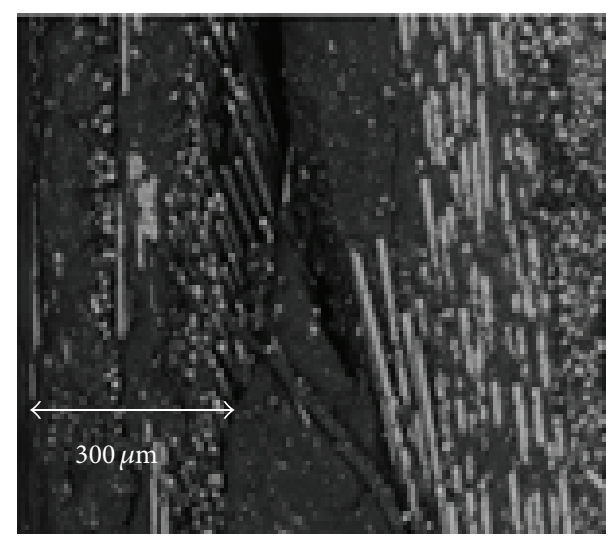

(b)

FIGURE 7: Observations with the SEM of composite material immersed in $\mathrm{NaOH}$ (a) after 40 hours and (b) after 120 hours.

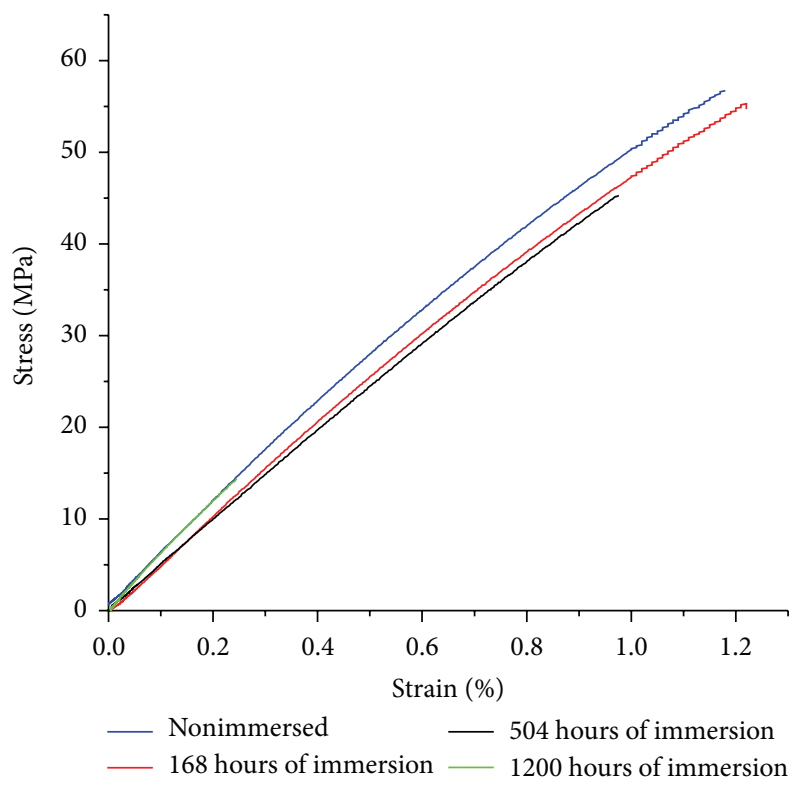

(a)

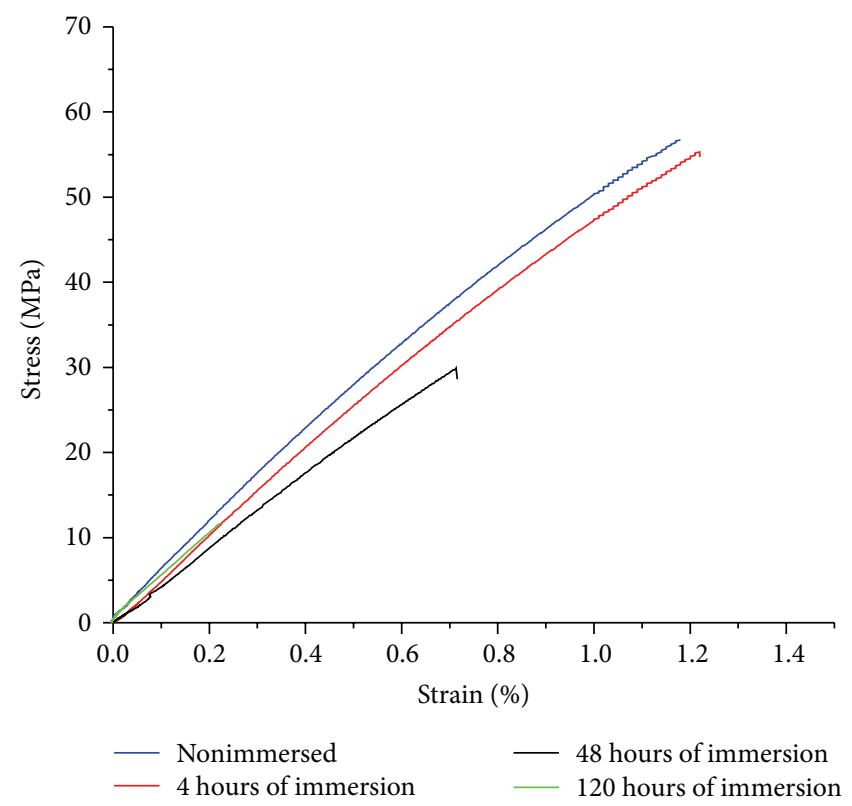

(b)

FIgURE 8: Stress-strain curves of the resin immersed in (a) $\mathrm{H}_{2} \mathrm{SO}_{4}$ and (b) $\mathrm{NaOH}$.

a quasi-linear behavior and a quasi-fragile rupture. Also, they show that the two mediums have little effect on rigidity of the resin although they have a significant effect on its ultimate resistance.

As regards the composite behavior, the curves of Figure 9 translate a whole linear behavior at the beginning of loading then no linear thereafter until the rupture. The general shape of these curves can be schematized by the diagram of Figure 10. This diagram translates two phases quite distinct from behavior: the first is linear and it translates the total behavior of the composite before any appearance of damage. As for the second phase, which is nonlinear, it represents the progressive transverse cracking of the mats plies. The transverse cracking of a mat ply stops when the maximum distance between two close cracks cannot ensure any more the transmission of effort by shearing at the level of the interface. It is noticed that the nonlinear field appears broader than the linear field. It is noticed, also, that the time of immersion affects a little the ultimate resistance and the strain at failure.

The evolution of the mechanical characteristics (resistance, failure strain, and the elastic modulus) of the resin and the composite according to the immersion time is illustrated by Figures 11 and 12 .

The curves in Figures 11(a), 11(b), and 11(c) show that the resin immersed in the sulphuric acid gains nearly $6 \%$ in resistance and $11 \%$ in failure strain after two weeks of immersion. For longer times of immersion, they fall to reach at 50 days of immersion $66 \%$ of loss in resistance and $63.15 \%$ of loss in failure strain. As for the elastic modulus, it does 


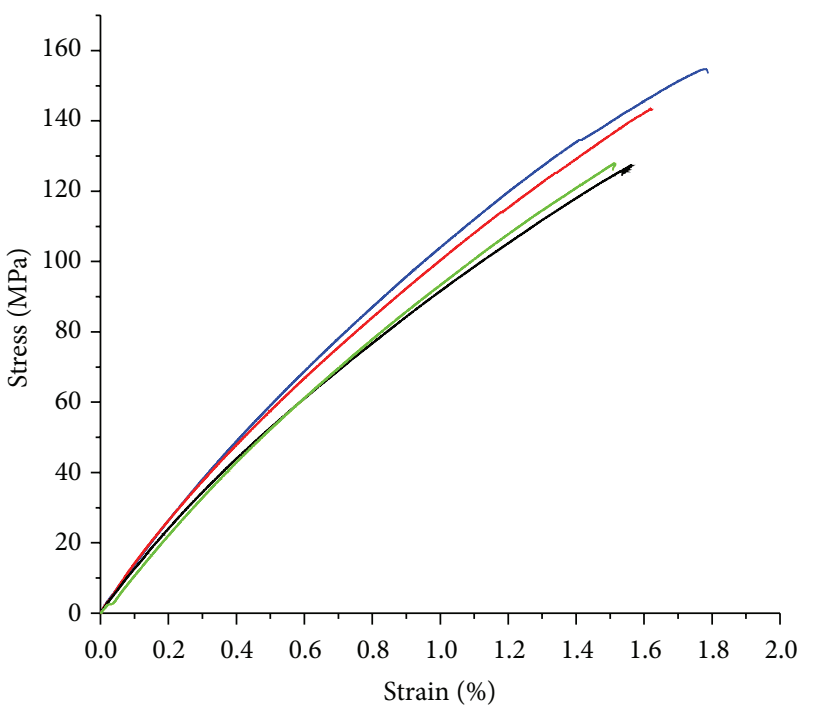

$\begin{array}{ll}- \text { Nonimmersed } & -504 \text { hours of immersion } \\ -168 \text { hours of immersion } \quad-\quad 1200 \text { hours of immersion }\end{array}$

(a)

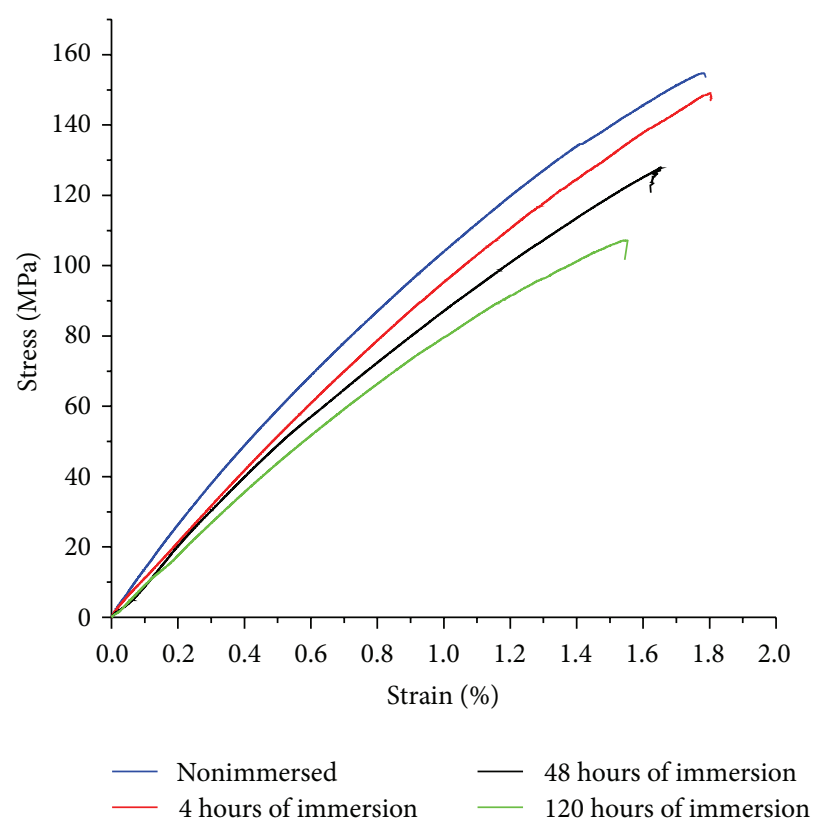

(b)

FIGURE 9: Stress-strain curves of composite material immersed in (a) $\mathrm{H}_{2} \mathrm{SO}_{4}$ and (b) $\mathrm{NaOH}$.

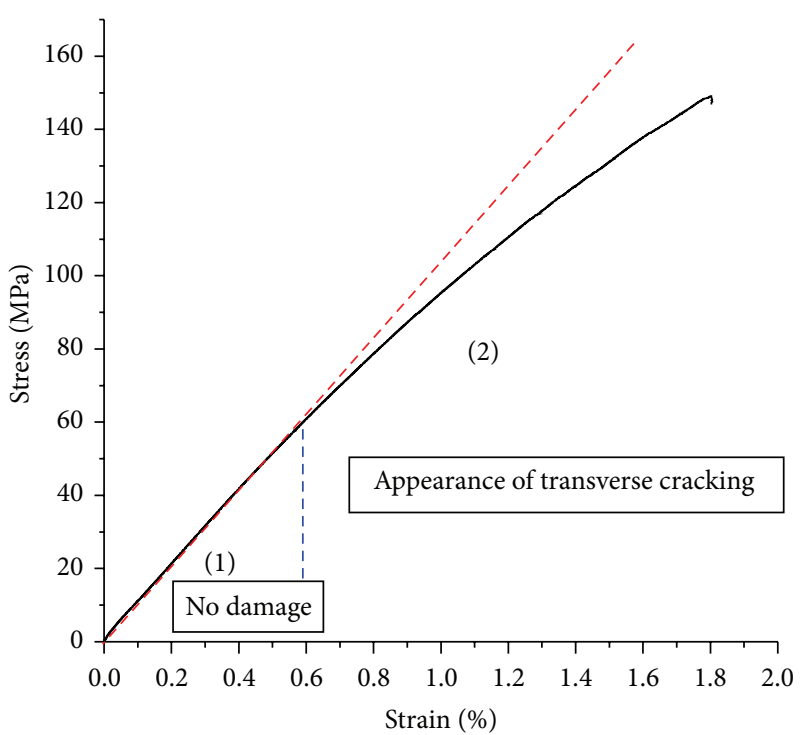

(1) Linear zone

(2) No linear zone

Figure 10: Damage of the composite by tensile test.

nothing but decrease with the time of immersion to reach $36 \%$ of loss at 50 days. As regards the composite immersed in $\mathrm{H}_{2} \mathrm{SO}_{4}$, the curves of Figure 11 show that resistance, the failure strain, and the elastic modulus decrease in a linear way with the time of immersion (after 50 days of immersion: approximately $15 \%$ of loss in resistance, $16 \%$ of loss in failure strain, and $6 \%$ of loss of the elastic modulus).
For the resin immersed in $\mathrm{NaOH}$, after a profit in resistance and failure strain during the first hours of immersion (approximately 36\% for resistance and $127 \%$ for the failure strain after 4 hours), a strong reduction of these two characteristics is attended which reaches at 120 hours of immersion: $78.5 \%$ for resistance and $75 \%$ for the failure strain (Figures 12(a) and 12(b)). In the same way, the elastic modulus shows a quasi-linear reduction with the time of immersion ( $42 \%$ to 120 hours). As for the composite immersed in $\mathrm{NaOH}$, Figures 12(a), 12(b), and 12(c) show stability, even a small improvement of resistance and failure strain at the beginning of immersion (a profit from approximately $1 \%$ of resistance and $2 \%$ of failure strain after 4 hours of immersion). Beyond 4 hours of immersion, resistance decreases in a linear way to reach, after 120 hours of immersion, the losses of $23.55 \%$. As for the failure strain, it will remain practically stable with $7 \%$ of reduction. As regards the elastic modulus, it only decreases, in a linear way, with the time of immersion to reach approximately $16 \%$ of loss at 120 hours.

4.5.2. Bending Tests. It should be recalled that the bending test of the composite was done according to the diagram illustrated by Figure 13 .

The results of the three-point bending test of resin and composite immersed in $\mathrm{H}_{2} \mathrm{SO}_{4}$ and $\mathrm{NaOH}$ are illustrated by Figures 14 and 15, respectively.

Figure 14 shows that the shape of the load-displacement curve of the resin under three-point bending test depends on the time of immersion and the medium of immersion. For the resin immersed in $\mathrm{H}_{2} \mathrm{SO}_{4}$ (Figure 14(a)), its behavior is linear until the rupture with a kind of material embrittlement, which results in a significant fall of displacement to the rupture. On the other hand, in the case of its immersion 

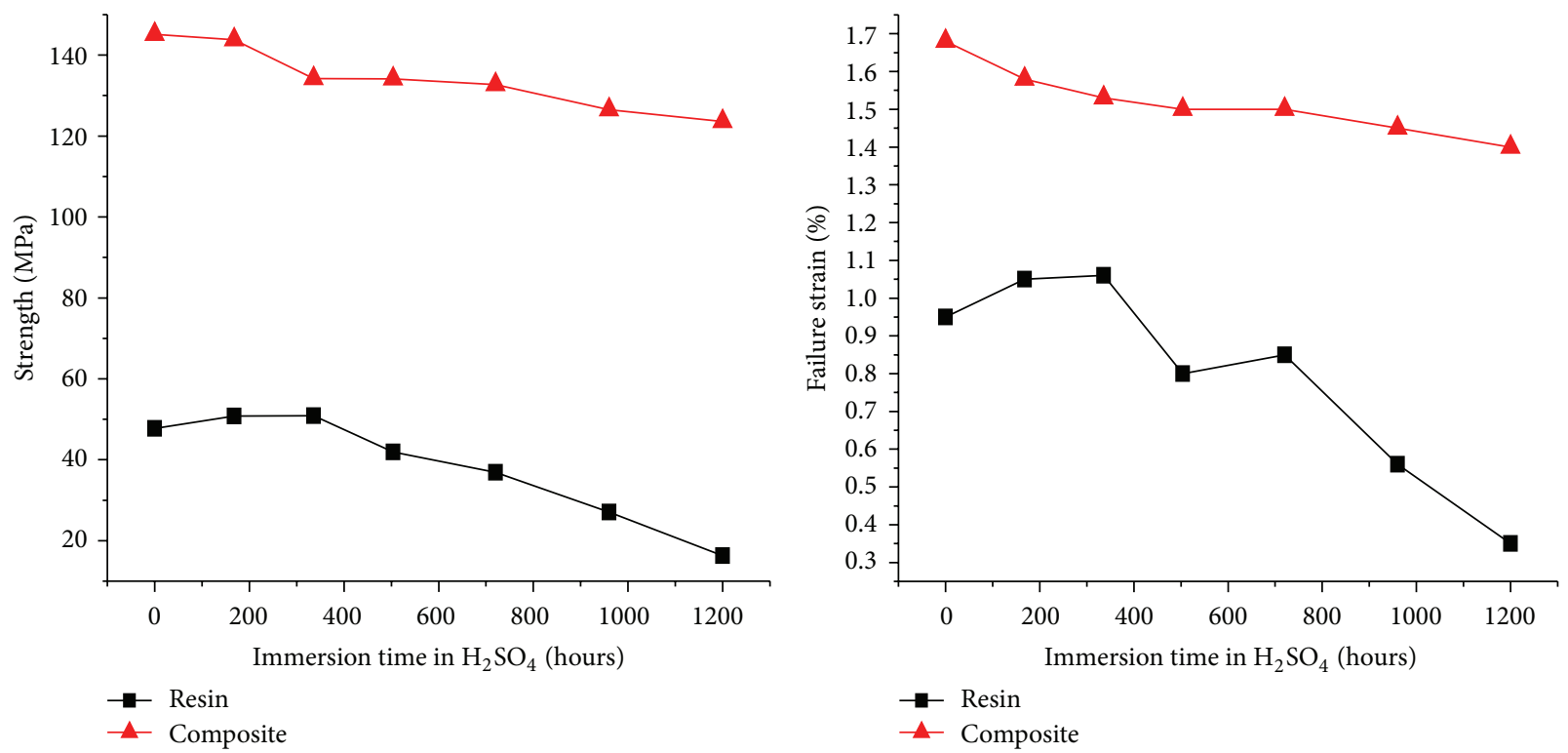

(a)

(b)

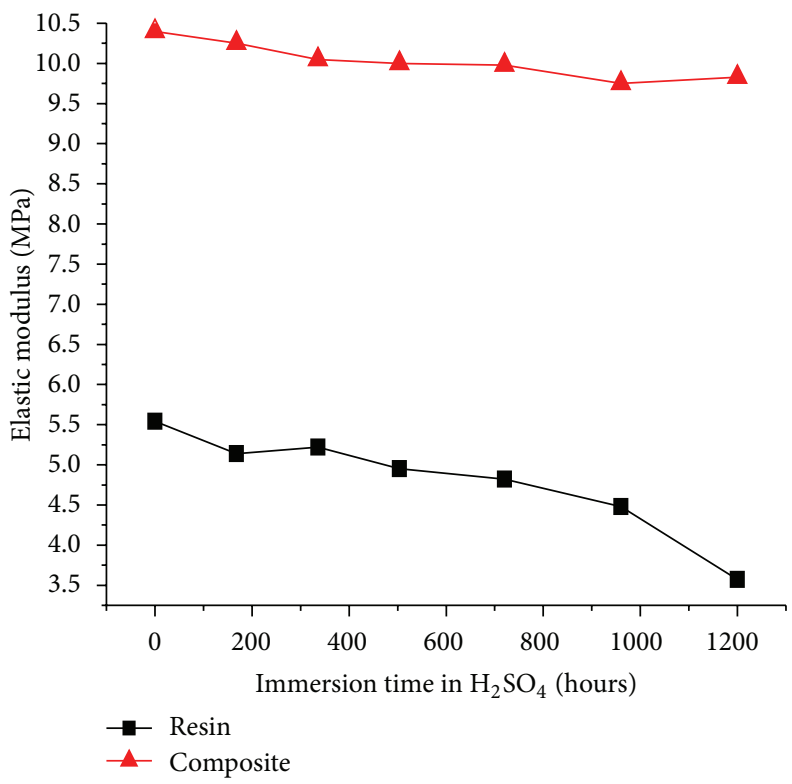

(c)

FIGURE 11: Evolution of the mechanical properties in traction of the resin and the composite: (a) strength, (b) failure strain, and (c) the elastic modulus according to the immersion time in $\mathrm{H}_{2} \mathrm{SO}_{4}$.

in $\mathrm{NaOH}$, the resin behaves in a linear way initially then in a nonlinear way while approaching the rupture. The nonlinear phase widened more with the increase of the time of immersion, which increases displacement at rupture (Figure 14(b)).

As regards the composite behavior under three-point bending test, the load-displacement curves of Figure 15 translate all three phases: a first elastic linear phase at the beginning of request and a second nonlinear phase until the top of the curve, corresponding to the progressive rupture of the 6 th fold the most tended. As for the third phase, it is located beyond the top of the curve. The brutal fall of the load recorded, just after summon, corresponds to the rupture of the 5 th fold (woven). This last phase translates a ruin into the staircase shape which explains that, after the woven rupture, there will remain still fibre bridges and mats (1st, $2 \mathrm{nd}$, 3rd, and 4 th plies) which will constitute a certain resistance with a low rigidity (Figure 16). It should be noted that the shapes of the curves are influenced by the mediums of immersion $\left(\mathrm{H}_{2} \mathrm{SO}_{4}\right.$ and $\mathrm{NaOH}$ ) and by time.

For better illustration of the effect of the acid and alkaline solutions on the mechanical behavior in inflection of material, an evolution of the characteristics in bending test to know the load and displacement at rupture of the resin alone 


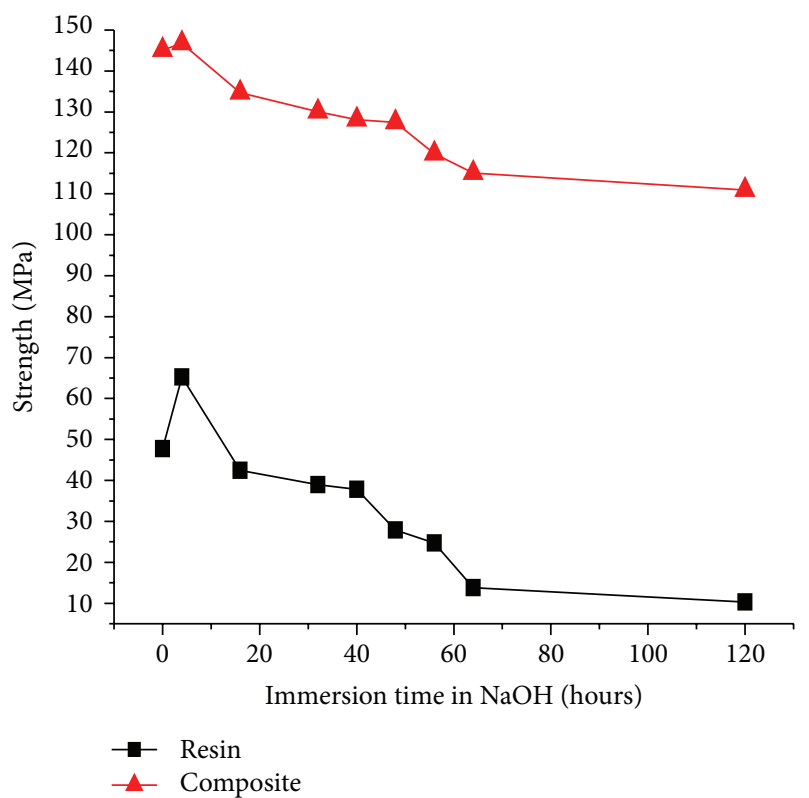

(a)

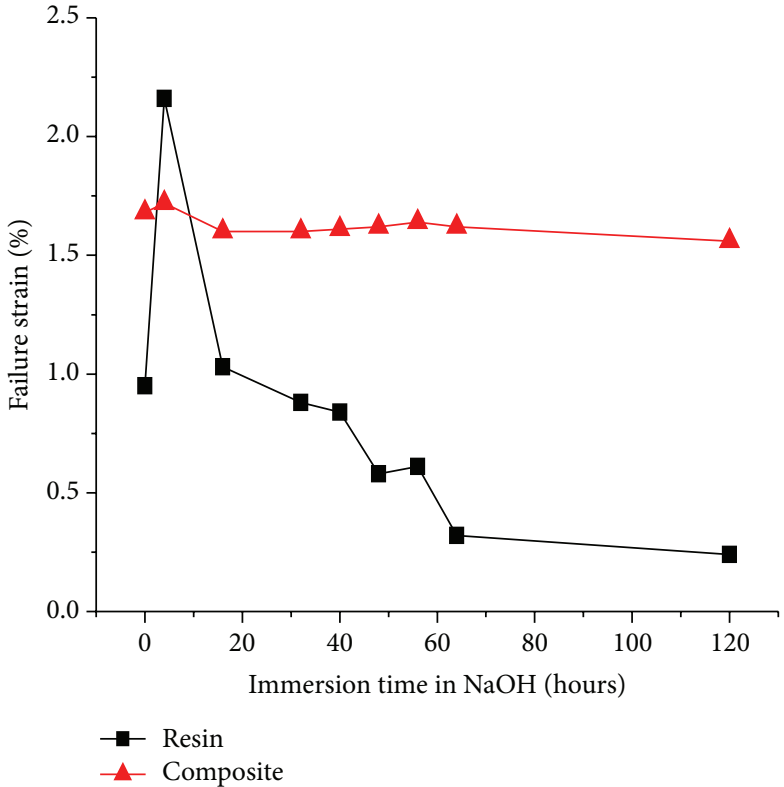

(b)

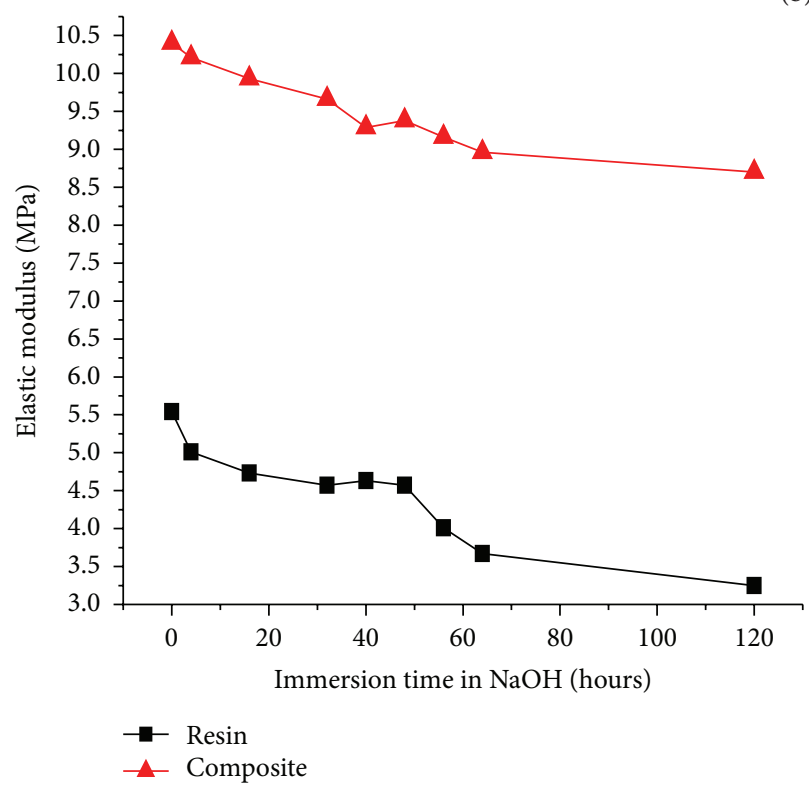

(c)

FIGURE 12: Evolution of the mechanical properties in traction of the resin and the composite: (a) strength, (b) failure strain, and (c) the elastic modulus of according to the immersion time in $\mathrm{NaOH}$.

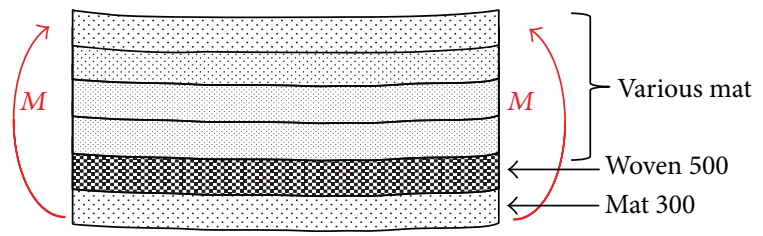

FIGURE 13: Bended composite.

and composite according to the immersion time in $\mathrm{H}_{2} \mathrm{SO}_{4}$ and $\mathrm{NaOH}$ is represented by Figures 17 and 18 .
The curves in Figures 17(a) and 17(b) show that the resin immersed in the sulphuric acid records strong and fast reduction in its mechanics properties under threepoint bending test (maximum loading and displacement corresponding). In the case of the resin immersed in $\mathrm{NaOH}$, the first moments of immersion correspond to profit in terms of maximum loading (approximately 10\% for 4 hours of immersion); then, the phenomenon is reversed and the maximum loading shows a more or less linear reduction according to the immersion time to reach $44 \%$ of loss for 120 hours (Figure 18(a)). When the maximum displacement 


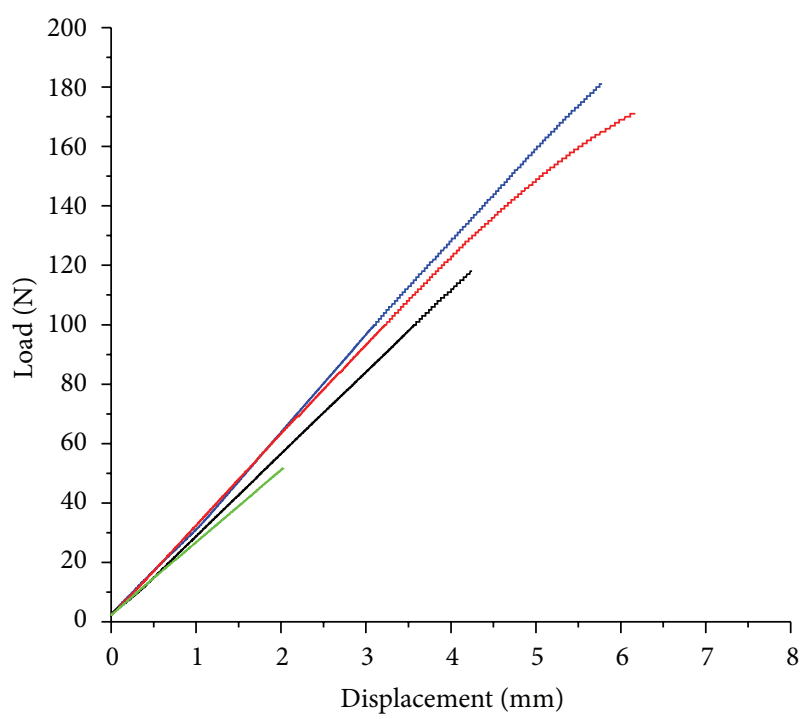

$\begin{array}{ll}- \text { Nonimmersed } & 504 \text { hours of immersion } \\ -168 \text { hours of immersion } & \quad 1200 \text { hours of immersion }\end{array}$

(a)

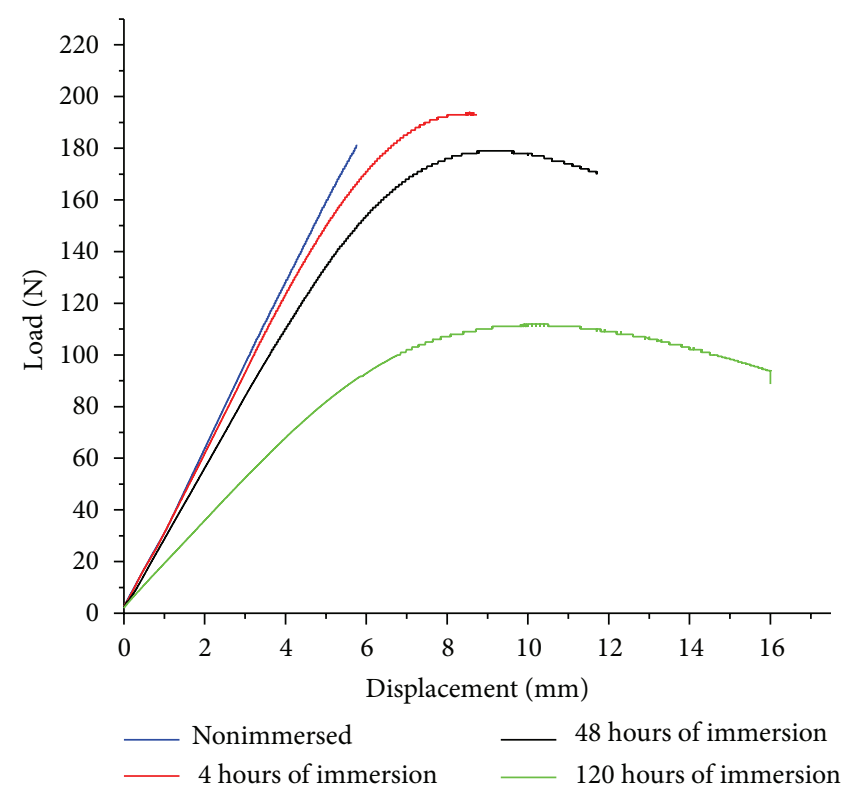

(b)

FIGURE 14: Load-displacement curves in three-point bending test of the resin at various immersion times in (a) $\mathrm{H}_{2} \mathrm{SO}_{4}$ and (b) $\mathrm{NaOH}_{\text {. }}$

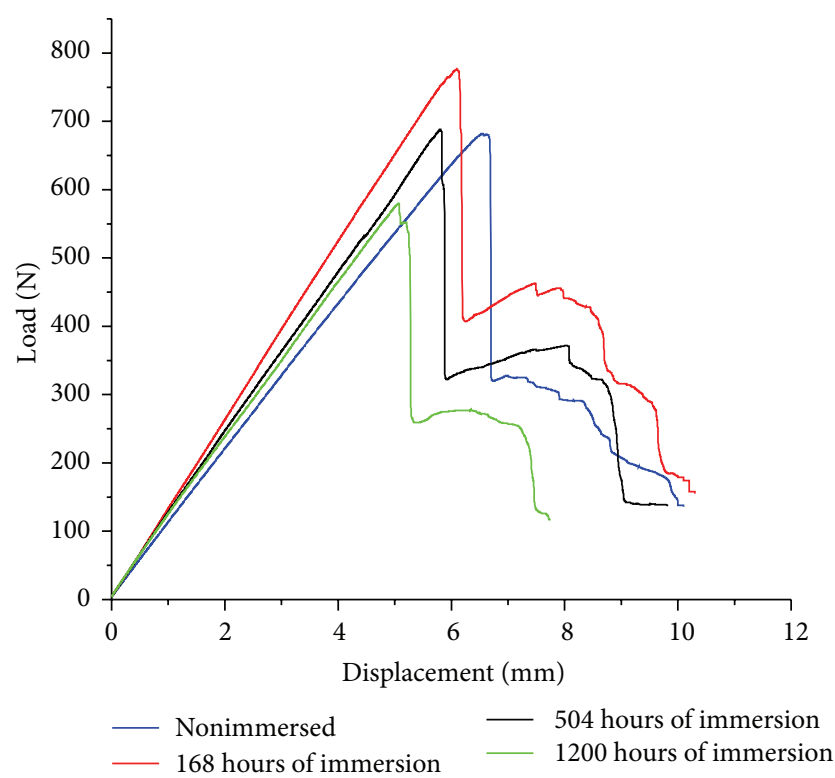

(a)

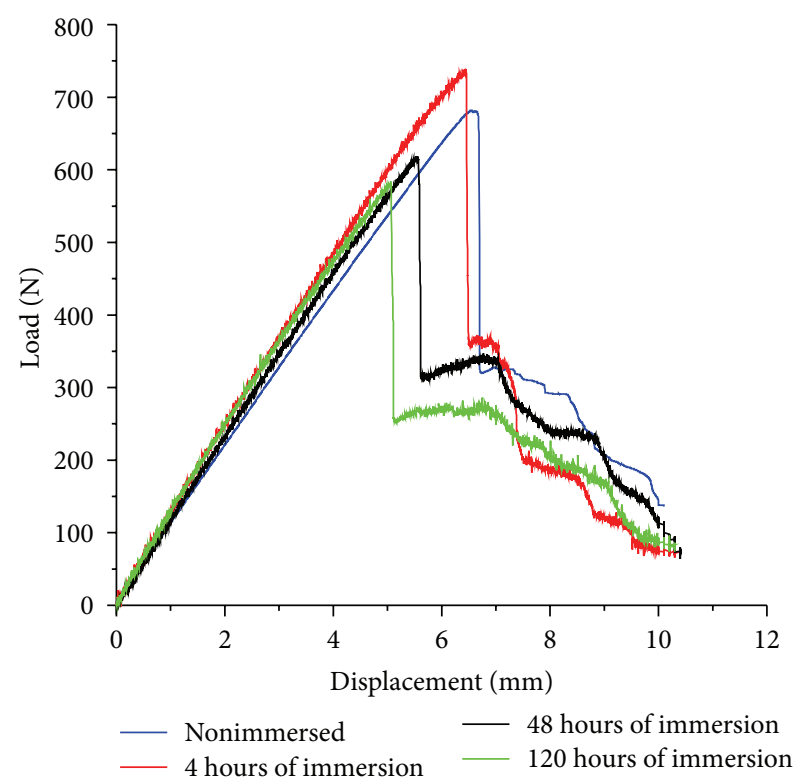

(b)

Figure 15: Load-displacement curves in three-point bending test of the composite at various immersion times in: (a) $\mathrm{H}_{2} \mathrm{SO}_{4}$ and (b) $\mathrm{NaOH}_{\text {. }}$

recorded of previous one showing a quasi-linear increase to reach a stage of stability after 64 hours of immersion.

As regards the residual behavior of the composite, it appears that the mechanical characteristics (maximum loading and displacement corresponding) start with a weak increase lasting the first moments of immersion for the two solutions $\left(\mathrm{H}_{2} \mathrm{SO}_{4}\right.$ and $\left.\mathrm{NaOH}\right)$. Then, they decrease in a quasilinear way until recording significant losses (11\% and 14\% of maximum loading loss and $16.4 \%$ and $15.6 \%$ of displacement loss in $\mathrm{H}_{2} \mathrm{SO}_{4}$ and $\mathrm{NaOH}$, resp.).

4.5.3. Discussion of the Results of the Mechanical Tests. The results of the mechanical tests showed a resistance profit during the first moments of immersion in the various solutions. The resistance profit recorded would be due to an additional crosslinking following a plasticization of 


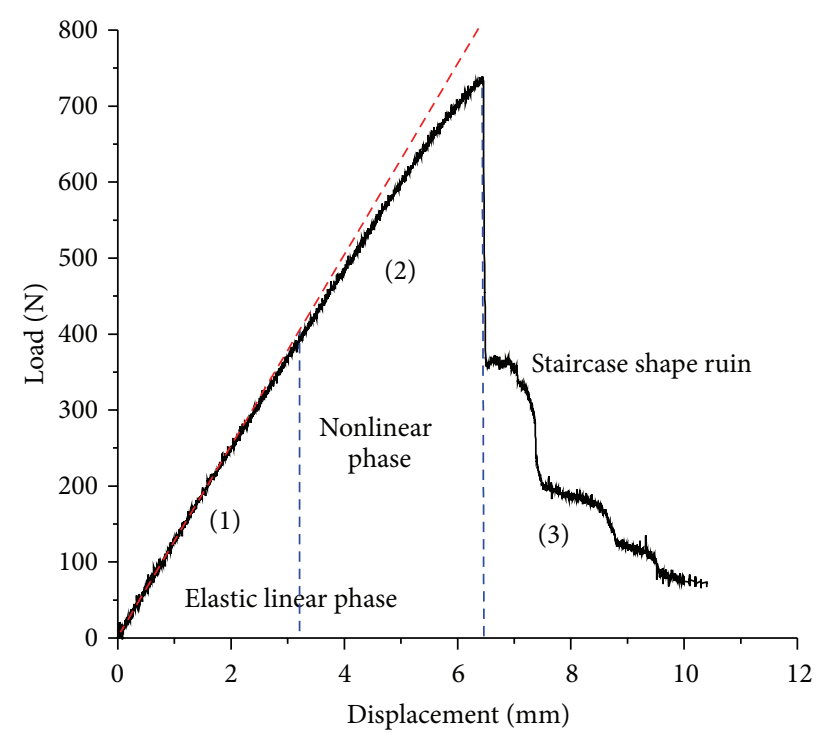

Figure 16: Damage of the composite by three-point bending test.

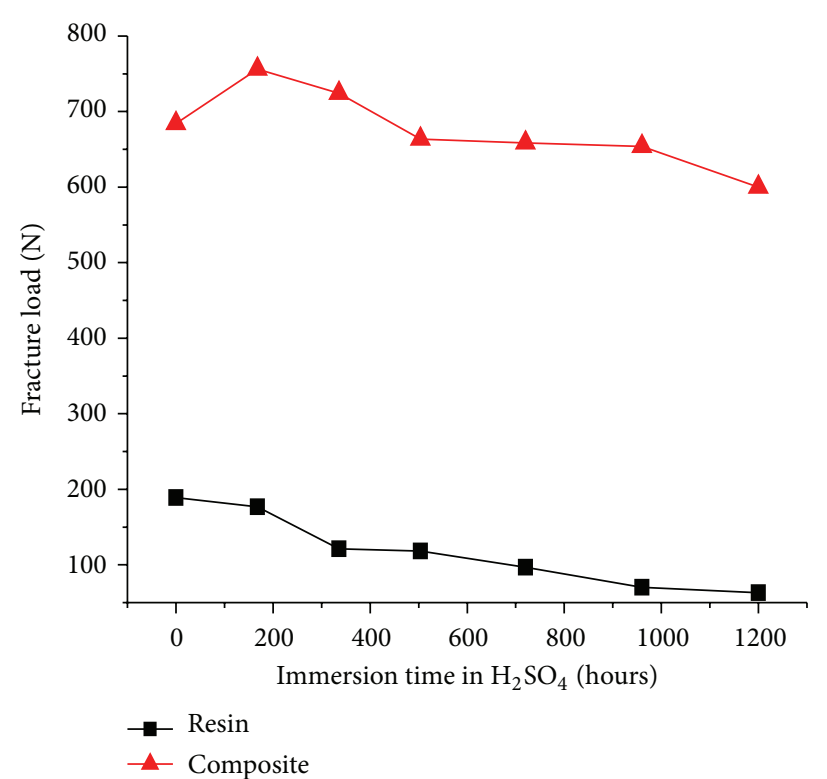

(a)

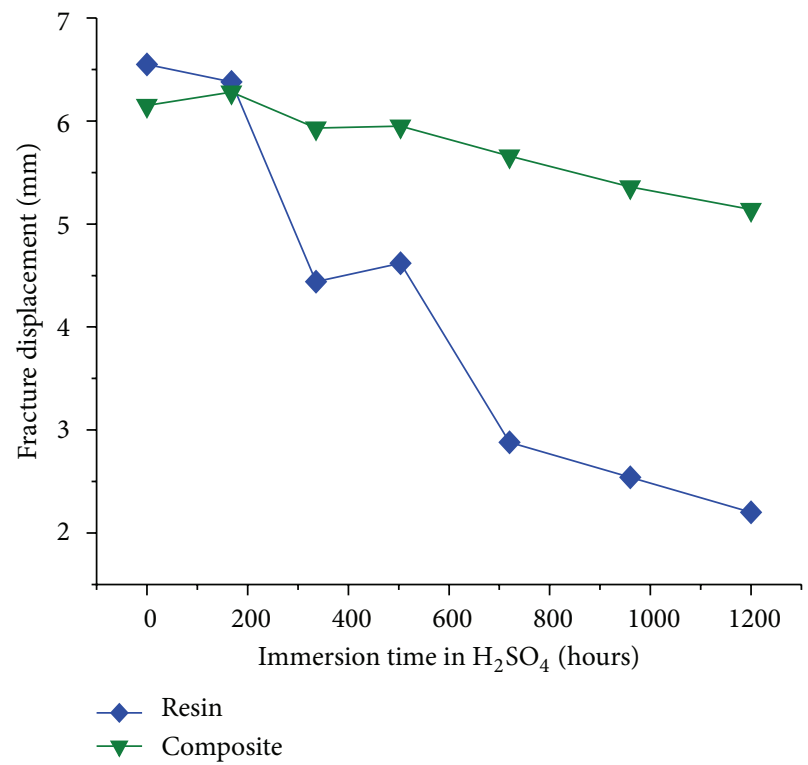

(b)

FIGURE 17: Load and displacement curves of the resin and composite materials: (a) the maximum loading and (b) maximum displacement versus immersion time in $\mathrm{H}_{2} \mathrm{SO}_{4}$.

the network by the solutions. This confirms the results of FT-IR analysis that showed that the crosslinking after the postcuring was incomplete. The effect of plasticization on the postcrosslinking was observed by Bagherpour et al. and Perrot $[5,6]$ which reported that plasticization by the liquids facilitates the phenomenon of postcrosslinking by increasing the probability of meeting the reactive sites. In fact, plasticization has a double effect: to increase resistance and ductility at the same time. The penetration of the solutions in polymer decreases the coherence of material and allows greater movements of molecules. This phenomenon appears macroscopically by a swelling of the network that is more relaxed and is manifested by a flexible material [9].

For longer times of immersion, the various materials (resin and composite) recorded losses of resistance and ductility. This report agrees well with the results reported by $[5,9,12,13]$. The losses of recorded resistance and ductility could be the consequence of several phenomena occurring simultaneously or successively such as chemical degradation (hydrolysis acid and alkaline that create cracks and blisters weakening the fibre/matrix interface) and the corrosion of fibre and the destruction of the fibre/matrix interphase. 


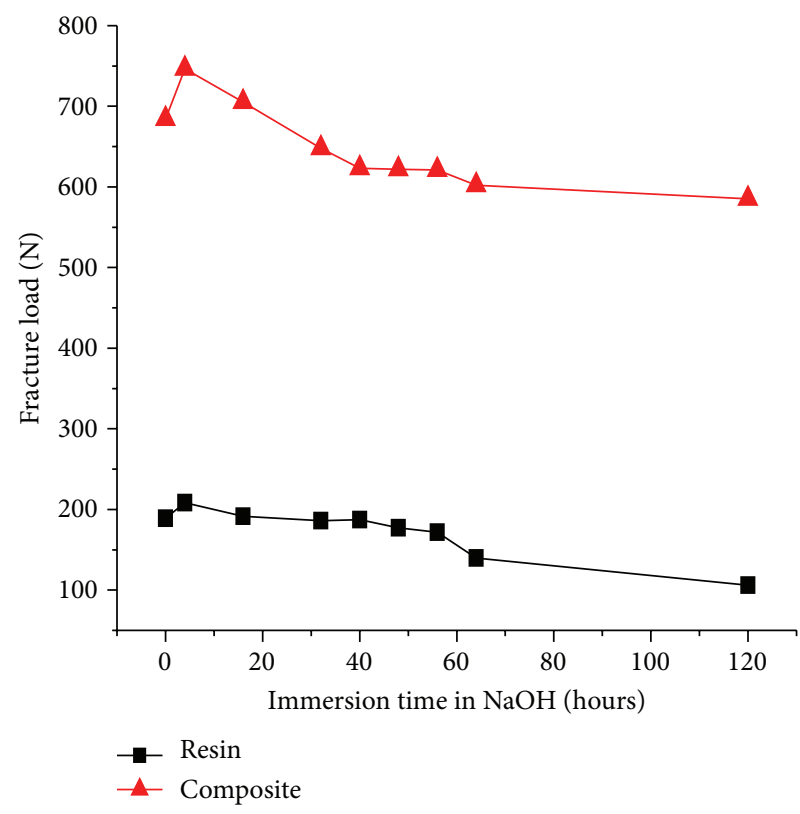

(a)

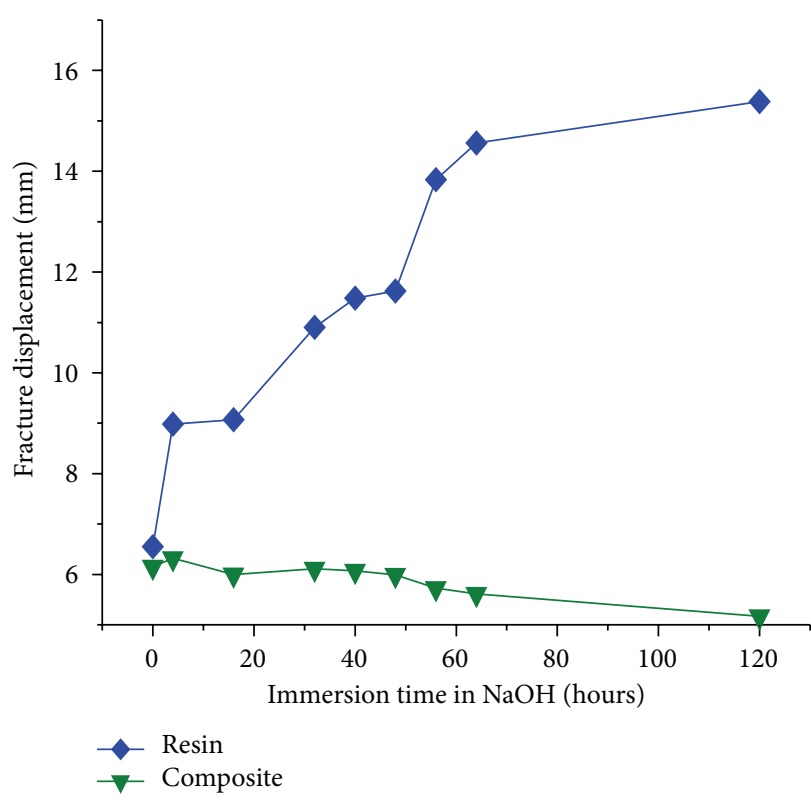

(b)

FIGURE 18: Load and displacement curves of the resin and composite material: (a) the maximum loading and (b) maximum displacement versus immersion time in $\mathrm{NaOH}$.

It should be known that the degradation progression towards the material heart could take time because it depends on porosity in general and on the connectivity of this porosity in particular. The behavior degradations were highlighted by the FT-IR and SAA analyses and the observations by the SEM.

\section{Conclusion}

The aim of this work was to study the behavior of a glass fibre/UP composite elaborated by hand layup process subjected to the attack of two corrosive solutions: $\mathrm{H}_{2} \mathrm{SO}_{4}$ and $\mathrm{NaOH}$. The results obtained show the following:

(i) In the $\mathrm{H}_{2} \mathrm{SO}_{4}$ acid, the resin and the composite shows pseudo-fikian diffusion. The mass uptake is due partly to the reaction of the resin with the water of the acid solution according to a hydrolysis phenomenon. Moreover, this hydrolysis will generate a cracking that facilitates the diffusion of the acid towards the fibre/matrix interface responsible for the glass fibres corrosion phenomenon.

(ii) For the immersion in $\mathrm{NaOH}$, the two materials present mass losses that are due to cuts of chains and the glass fibres corrosion. The cuts of chains are generated by the hydrolysis of the ester groupings of the resin catalyzed by $\mathrm{OH}^{-}$ion of the medium.

(iii) The activation of the phenomena of chemical degradation by acid and basic hydrolysis of the resin is confirmed by analysis FT-IR. This degradation takes place by macromolecular scissions of chains on the level of the $\mathrm{C}-\mathrm{O}-\mathrm{C}$ connections for the two mediums of immersion and with a formation of new final groupings $\mathrm{OH}$ and $\mathrm{COOH}$ in the case of the acid medium. Chemical degradation is accentuated by the incomplete crosslinking of the unsaturated polyester resin.

(iv) The glass fibres degradation by the solutions $\mathrm{H}_{2} \mathrm{SO}_{4}$ and $\mathrm{NaOH}$ takes place by a process of ions exchange or by a process of leaching and that in a more aggressive way in the acid. This result is revealed, also, by SAA.

(v) The fibre/matrix interface is reached as of the first hours of immersion in the acid solution and at approximately 40 hours of immersion in the alkaline solution. Cracking is initiated in the resin then it is propagated towards the fibre/matrix interface by generating the washing away of fibres. These various reports were highlighted by the gravimetric analysis and the observations by SEM.

(vi) The presence of the pores (of rather significant size) in material after its elaboration influences the diffusion kinetics of the acid and alkaline solutions and contributes to the mechanical degradation of material.

(vii) The resistance and ductility losses revealed by the mechanical tests of the samples immersed in the two mediums of immersions are the result of a complex mechanism degradation bringing into play several phenomena such as the resin hydrolysis, the fibre corrosion, and the degradation of the fibre/matrix interface, in addition to the structural defects due to the implementation technique. 


\section{Conflict of Interests}

The authors declare that they have no conflict of interests.

\section{References}

[1] H. Jeong, "Effects of voids on the mechanical strength and ultrasonic attenuation of laminated composites," Journal of Composite Materials, vol. 31, no. 3, pp. 276-292, 1997.

[2] X. Gu, D. Raghavan, T. Nguyen, M. R. VanLandingham, and D. Yebassa, "Characterization of polyester degradation using tapping mode atomic force microscopy: exposure to alkaline solution at room temperature," Polymer Degradation and Stability, vol. 74, no. 1, pp. 139-149, 2001.

[3] F. Poulard, Adhesion of polyamide 11: mechanism and hygrothermal ageing [thesis], School of the Mines, Paris, France, 1998.

[4] S. M. Kumar, N. Sharma, and B. C. Ray, "Acid degradation of FRP composites," in Proceedings of the National Conference on Developments in Composites ( $N c d c$ '07), National Institute of Technology, Rourkela, India, April 2007.

[5] S. Bagherpour, R. Bagheri, and A. Saatchi, "Effects of concentrated $\mathrm{HCl}$ on the mechanical properties of storage aged fiber glass polyester composite," Materials and Design, vol. 30, no. 2, pp. 271-274, 2009.

[6] Y. Perrot, Influence properties of the matrix on the mechanical behavior of composite materials glass/polyester used in naval construction-case of the resins polyester limiting the styrene emissions [thesis], School of the Mines, Paris, France, 2006.

[7] I. Mouallif, A. Latrach, M. Chergui, A. Benali, M. Elghorba, and N. Barbe, "Effet du vieillissement sulfatique sur les propriétés hygrothermiques et mécaniques des composites polyester/fibre de verre," ScienceLib Editions Mersenne, vol. 5, no. 130116, 2013.

[8] J. Lebel, Etude des effets de l'humidité sur les composites recouverts de gelcoat, Mémoire de maitrise des sciences appliquées, Ecole polytechnique, Montréal, Canada, 1999.

[9] E. P. Gellert and D. M. Turley, "Seawater immersion ageing of glass-fibre reinforced polymer laminates for marine applications," Composites Part A: Applied Science and Manufacturing, vol. 30, no. 11, pp. 1259-1265, 1999.

[10] K. de la Caba, P. Guerrero, A. Eceiza, and I. Mondragon, "Kinetic and rheological studies of two unsaturated polyester resins cured at different temperatures," European Polymer Journal, vol. 33, no. 1, pp. 19-23, 1997.

[11] H. P. Abeysinghe, W. Edwards, G. Pritchard, and G. J. Swampillai, "Degradation of crosslinked resins in water and electrolyte solutions," Polymer, vol. 23, no. 12, pp. 1785-1790, 1982.

[12] S. W. Tsui and F. R. Jones, "The effect of damage on the durability of a sand-filled GRP sewer lining under acidic stress corrosion conditions," Composites Science and Technology, vol. 44, no. 2, pp. 137-143, 1992.

[13] T. Katayama, Y. Hosokawa, and Y. Sakamoto, "Degradation of FRP immersed in sulfuric acid aqueous solution: the proposal of the evaluation method which can consider the sulfuric acid aqueous solution temperature, concentration and the test piece width," Journal of Materials Processing Technology, vol. 143-144, pp. 677-681, 2003. 

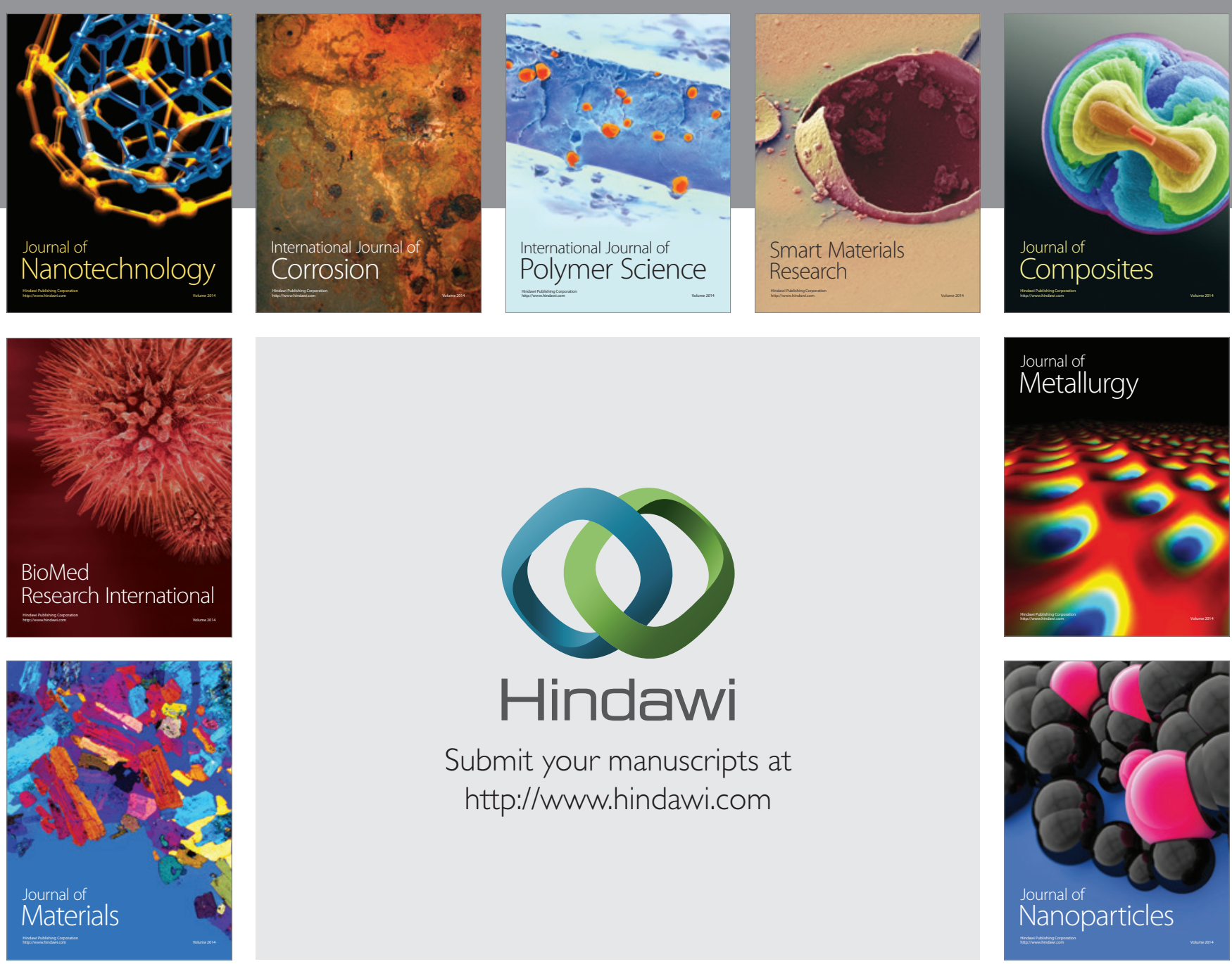

Submit your manuscripts at http://www.hindawi.com
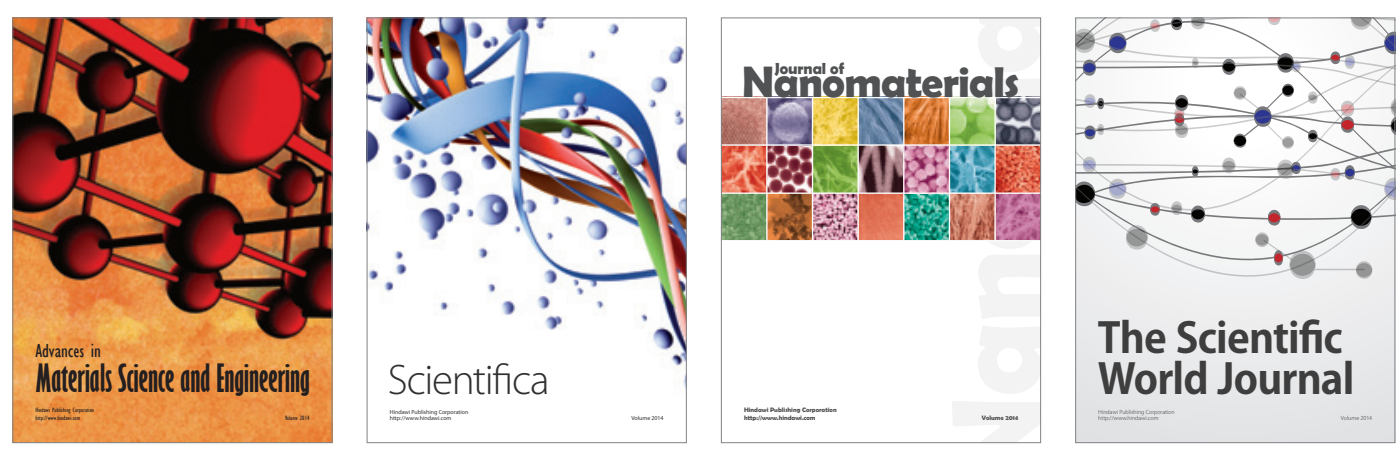

\section{The Scientific World Journal}
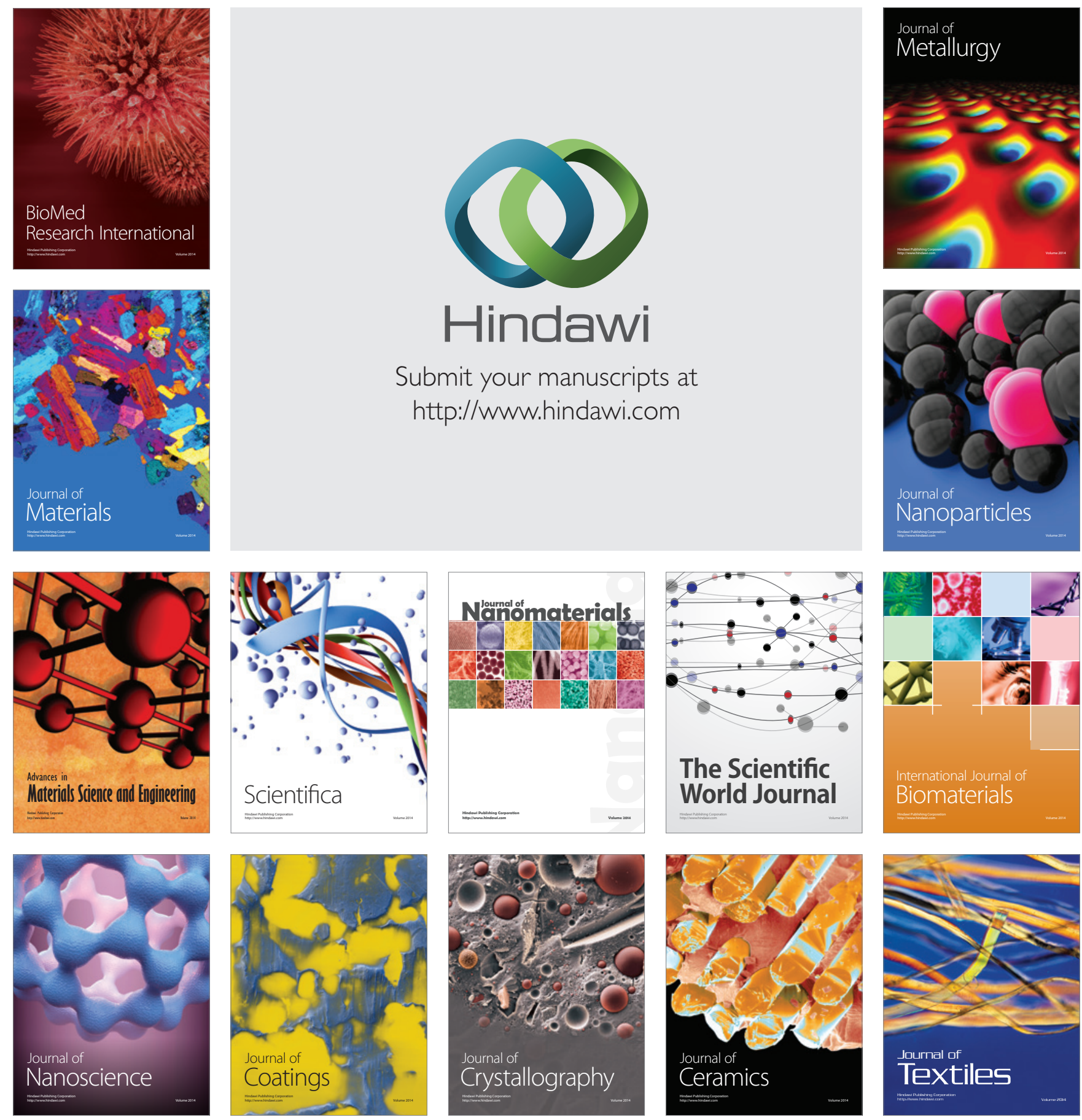